\title{
Failure to Predict High-risk Kawasaki Disease Patients in a Population-based Study Cohort in Germany
}

\author{
André Jakob, MD, * Rudiger von Kries, MD, † Judith Horstmann, $\neq$ Markus Hufnagel, MD, $\S$ Brigitte Stiller, MD, $\neq$ \\ Reinhard Berner, MD, 9 Eva Schachinger, $\neq$ Karoline Meyer, $\neq$ and Viola Obermeier, PhD $\dagger$
}

Background: Diverse scores on high-risk Kawasaki disease (KD) patients have proven a good prognostic validity in the Japanese population. However, data on non-Japanese have been inconclusive. Do the Kobayashi, Egami and Sano scores or application of up-to-date statistical methods (Random Forest) predict response to standard intravenous immunoglobulin (IVIG) therapy and the risk of persistent coronary artery aneurysm (CAA) in patients with $\mathrm{KD}$ in a mainly Caucasian population in Germany?

Methods: Data on 442 children (German population-based survey, 2013 and 2014) were used to assess the prognostic validity of the Kobayashi, Egami and Sano scores for being refractory to IVIG treatment and for predicting the risk of persistent CAA. Additionally, an up-to-date statistical approach (Random Forest) was applied to identify a potentially more valid score.

Results: A total of 301 children were eligible for assessment of their response to IVIG treatment. Among those, 177 children were followed-up for 1 year to identify persistent CAA. Although all scores were significantly associated with being refractory to IVIG (relative risk range between 2.32 and 3.73), the prognostic properties were low (likelihood ratio positive: $1.83-4.57$; sensitivity in the range of $0.28-0.53$ ). None of the scores was a significant predictor of CAA 1 year after acute illness. Application of sta-

\section{Accepted for publication January 29, 2018}

From the *Department of Pediatric Cardiology and $\dagger$ Department of Epidemiology, Institute of Social Pediatrics and Adolescent Medicine, Ludwig-Maximilians-University of Munich, Munich, Germany; $\ddagger$ Department of Congenital Heart Disease and Pediatric Cardiology, University Heart Center Freiburg, Freiburg, Germany; §Division of Pediatric Infectious Diseases and Rheumatology, Department of Pediatrics and Adolescent Medicine, University Medical Center, Medical Faculty, University of Freiburg, Freiburg, Germany; and \Department for Pediatrics, Universitätsklinikum Carl Gustav Carus, Technische Universität Dresden, Dresden, Germany.

Clinical Trial Registration: German clinical trial registration, DRKS00010071 http://apps.who.int/trialsearch/Trial2.aspx?TrialID=DRKS00010071

A.J. has received funding for this study by a grant from the German heart foundation. Surveillance of Kawasaki disease was supported by a grant of the German Heart Research Foundation. The principal investigator (André Jakob) had full access to all the data in the study and takes responsibility for the integrity of the data and the accuracy of the data analysis.

The authors have no conflicts of interest to disclose.

A.J. conceived and designed the study, drafted the article and approved the final article as submitted. R.v.K. contributed to the study design, drafted the article, interpreted the statistical analysis and approved the final article as submitted. J.H. contributed to the data collection, study design and statistical analysis, as well as approved the final article as submitted. M.H. contributed to the study design and interpretation of data, served on the adjudicating committee and approved the final article as submitted. B.S. contributed to the study design and interpretation of data, served on the adjudicating committee and approved the final article as submitted. R.B. contributed to the study design, served on the adjudicating committee and approved the final article as submitted. E.S. contributed to the data collection and study design, as well as approved the final article as submitted. K.M. contributed to the data collection and study design, as well as approved the final article as submitted. V.O. conducted the statistical analysis, contributed to drafting the article and approved the final article as submitted.

Address for correspondence André Jakob, MD, Department of Pediatric Cardiology, Ludwig-Maximilian-University of Munich, Marchioninistr 15, D-81377 Munich, Germany. E-mail: andre.jakob@med.uni-muenchen.de.

Supplemental digital content is available for this article. Direct URL citations appear in the printed text and are provided in the HTML and PDF versions of this article on the journal's website (www.pidj.com).

Copyright (C) 2018 Wolters Kluwer Health, Inc. All rights reserved.

ISSN: 0891-3668/18/3709-0850

DOI: $10.1097 /$ INF.0000000000001923 tistical analysis such as Random Forest did not yield a more valid score. Conclusions: None of the available scores appears to be appropriate for identifying high-risk Caucasian children with $\mathrm{KD}$ who might need intensified therapy.

Key Words: Kawasaki disease, risk scores, Caucasian

(Pediatr Infect Dis J 2018;37:850-855)

$\mathrm{K}_{\mathrm{e}}^{\mathrm{a}}$ awasaki disease (KD) is an acute febrile vasculitis of unknown etiology. The process of vascular inflammation is especially evident at the coronary artery level. This accounts for persistent coronary artery aneurysms (CAAs) with a high impact on longterm morbidity and mortality. Most, but not all affected children respond to a first intravenous immunoglobulin (IVIG) treatment. Response to IVIG treatment has been found to be a negative predictor for incident and persistent CAA. ${ }^{1}$ Currently, prediction of failure to respond to IVIG treatment is considered crucial for the purpose of identifying children who may need early supplementary immunosuppressive therapy. Although additional use of corticosteroids may have a positive impact on the course of fever and inflammation, ${ }^{2,3}$ a beneficial effect on the aneurysm rate was only observed in high-risk Japanese children ${ }^{46}$ identified by the Kobayashi score.

The Kobayashi score and other scores $\left(\mathrm{Egami}^{7}{ }^{7} \mathrm{Sano}^{8}\right)$ have been evaluated for prediction of being refractory to initial IVIG treatment in Japanese children. Data on the ability of these scores to validly predict response to standard IVIG therapy outside Japan has been limited. Additionally, the association between response to therapy and risk of developing CAA has been ambiguous. ${ }^{9}{ }^{10}$ The latest scientific statement from the American Heart Association (AHA) from the year 2017 only recommended the adjunctive use of corticosteroids when high-risk patients can be clearly identified. ${ }^{11}$

From 2013 to 2014, a German study collected active surveillance data on 442 children with KD. The study addressed the following questions:

In a primarily Caucasian population in Germany, how well do the Kobayashi and other scores predict first response to standard IVIG therapy and the risk of persistent CAA in patients with KD? Does the application of up-to-date statistical methods such as Random Forest allow for the determination of a highly predictive score in this population?

\section{PATIENTS AND METHODS}

Nationwide active surveillance through the hospital-based German Pediatric Surveillance Unit (ESPED) was used to recruit eligible KD patients. For the years 2011 and 2012, the incidence of KD in Germany (children $<5$ years) recently has been determined to be 7.2 in 100,000. ${ }^{12}$ Between January 1, 2013, and December 31, 2014, 442, presumed cases of KD were reported in Germany. Pseudonymous identifiers were employed in these ESPED reports. Reporting physicians were sent a standardized questionnaire explicitly requesting all parameters required for analysis. For numeric parameters, such as laboratory values, the reporting physicians were asked to document the measured values along with their respective units. For categorical parameters, 
correspondents were provided the option of checking either "yes" or "no." Additionally, through a written informed consent request sent by the treating physician, parents were asked whether they would agree to the disclosure of their children's identities for the study. In the cases where consent was provided, we validated the questionnaire data via discharge letters, recorded laboratory values and echocardiographic findings. Due to data protection regulations, follow-up only was possible in cases where parents had provided written consent. The ESPED reports were used to assess the diagnostic validity of Kobayashi and other scores in their ability to predict response to initial IVIG treatment. Due to the need for informed consent, long-term risk for persistent CAA was evaluated only in children with known identities. Exclusion criteria were: failure to comply with the clinical case definition; IVIGuntreated patients; steroid administration concurrent with the first IVIG therapy ( \pm 2 days); and, in cases where neither "yes" nor "no" was ticked on the questionnaire, uncertain steroid exposure. (In the context of the study, steroid administration was considered a confounder regarding clinical outcome.) Approval for the study was provided by the Ethics Committee of the University of Freiburg, in accordance with the ethical standards to the Declaration of Helsinki.

\section{DEFINITIONS}

\section{Kawasaki Disease}

AHA guidelines ${ }^{1}$ were used to classify complete and incomplete KD cases. Complete cases were defined as those with persistent fever for $\geq 5$ days or fever that resolved in $<5$ days in response to IVIG treatment. Additionally, display of at least 4 principal clinical features was required: (1) changes in extremities; (2) polymorphous exanthema; (3) bilateral conjunctival inflammation without exudate; (4) changes in the lips and oral cavity and (5) cervical lymphadenopathy. Incomplete cases included those with fever and those showing fewer than 4 clinical features but with detection of CAAs. As in other population-based surveillance studies, ${ }^{13}$ diagnosis of CAA was determined based on the clinical judgment of the reporting physician. In Germany, 2 criteria for aneurysms are applied. The first criteria follow those of the Japanese Ministry of Health, which defines aneurysms as either a lumen $>3 \mathrm{~mm}$ in children younger than 5 years, as a diameter 1.5 times the size of the surrounding segment, or as a clearly irregular lumen. The second criteria are defined as a $\mathrm{Z}$ score of $>2.5$ for one of the coronary arteries. ${ }^{14}$ In accordance with AHA guidelines, cases with fever persisting for longer than 36 hours and therefore given a second dose of IVIG were defined as "refractory to IVIG."

\section{Kobayashi Score}

The Kobayashi score assigns 2 points for each of the following: (1) sodium $\leq 133 \mathrm{mmol} / \mathrm{L}$; (2) days of illness before initial treatment $\leq 4$; (3) aspartate aminotransferase (AST) $\geq 100$ IU/L and (4) neutrophil count $\geq 80 \%$. Additionally, the score assigns one point for fulfilling the following criteria: (5) C-reactive protein (CRP) $\geq 10 \mathrm{mg} / \mathrm{dL}$; (6) age $\leq 12$ months and (7) platelet count $\leq 30.0 \times 10^{4} / \mathrm{mm}^{3}$. In the literature, different cutoff values have been applied for labeling high-risk patients (ie, $>3$ and $>4$ ).

\section{Sano Score}

The Sano score labels patients as high risk when at least 1 of the 2 following criteria apply: (1) CRP $\geq 7.0 \mathrm{mg} / \mathrm{dL}$; (2) bilirubin $\geq 0.9 \mathrm{mg} / \mathrm{dL}$ or $(3)$ AST $\geq 200 \mathrm{IU} / \mathrm{L}$.

\section{Egami Score}

The Egami score assigns patients to the high-risk group when at least 3 of 6 possible points apply: (1) age $\leq 6$ months (1 point); (2) days of illness at initial treatment $\leq 4$ ( 1 point); (3) platelet count $\leq 30.0 \times 10^{4} / \mathrm{mm}^{3}$ ( 1 point); (4) CRP $\geq 8 \mathrm{mg} / \mathrm{dL}$ (1 point) and (5) alanine aminotransferase $\geq 80 \mathrm{IU} / \mathrm{L}$ ( 2 points).

In our main analysis, missing values in one of the required laboratory parameters were rated as "absence of the risk factor." A sensitivity analysis used only cases with complete information on all risk factors.

\section{STATISTICAL ANALYSIS}

Descriptive statistics were performed using the statistical software R (R 3.1.0). For all outcomes "refractory to IVIG," "aneurysm after 4 weeks" and "aneurysm after 1 year," we assessed the risk increase related to high-risk classification in 3 scores (Kobayashi, Egami und Sano). We additionally assessed indicators of the prognostic value - that is, sensitivity, specificity, positive and negative prognostic value and positive likelihood ratio (LR+). On this basis, we calculated $95 \%$ confidence interval (CI) for relative risk and likelihood risk. In a sensitivity analysis, the respective risk ratios and $\mathrm{LR}+$ also were determined for cases that had obtained complete information regarding the defining score parameters (Table, Supplemental Digital Content 1, http://links.lww.com/INF/ C969). Additional sensitivity analyses were conducted including all eligible KD cases (Tables, Supplemental Digital Content 3-5, http://links.lww.com/INF/C971; http://links.lww.com/INF/C972; http://links.lww.com/INF/C973).

The relative risk for being refractory to IVIG, along with that for coronary aneurysms after 4 weeks and after 1 year, was assessed in relation to the 3 risk scores (Tables 1 and 2).

To develop a potentially more discriminating score for defining high-risk groups in non-Japanese children, our study attempted-via univariate analysis - to identify clinical, echocardiographic and laboratory parameters significantly associated with being refractory to initial IVIG treatment (Table 3). For

TABLE 1. CAA After $4 \mathrm{wk}(\mathrm{n}=22 / 175)$ : Numbers at High Risk for CAA After $4 \mathrm{wk}$ According to Different Scores and Indicators of Prognostic Validity for the Respective Scores

\begin{tabular}{|c|c|c|c|c|c|c|c|}
\hline $\begin{array}{l}\text { High-risk } \\
\text { According } \\
\text { to Score }\end{array}$ & $\begin{array}{c}\text { Aneurysm } \\
\text { High-risk } \\
\text { Children } \\
\text { n }(\%)\end{array}$ & $\begin{array}{c}\text { Relative } \\
\text { Risk: High- vs. } \\
\text { Low-risk Cases } \\
(95 \% \text { CI })\end{array}$ & Sensitivity & Specificity & $\begin{array}{c}\text { Positive } \\
\text { Predictive } \\
\text { Value }\end{array}$ & $\begin{array}{l}\text { Negative } \\
\text { Predictive } \\
\text { Value }\end{array}$ & $\begin{array}{c}\text { Positive } \\
\text { Likelihood } \\
\text { Ratio }(95 \% \mathrm{CI})\end{array}$ \\
\hline $\begin{array}{l}\text { Kobayashi }>4 \\
\mathrm{n}=37\end{array}$ & 7 (19) & $1.74(0.77-3.95)$ & 0.32 & 0.80 & 0.19 & 0.89 & $1.60(0.81-3.24)$ \\
\hline $\begin{array}{l}\text { Kobayashi }>3 \\
\mathrm{n}=60\end{array}$ & $11(18)$ & $1.92(0.88-4.16)$ & 0.50 & 0.68 & 0.18 & 0.90 & $1.56(0.97-2.52)$ \\
\hline $\begin{array}{l}\text { Sano } \\
\mathrm{n}=18\end{array}$ & $5(28)$ & $2.57(1.08-6.12)$ & 0.23 & 0.92 & 0.28 & 0.89 & $2.88(1.06-6.78)$ \\
\hline $\begin{array}{l}\text { Egami } \\
n=49\end{array}$ & $9(18)$ & $1.78(0.81-3.90)$ & 0.41 & 0.74 & 0.18 & 0.90 & $1.58(0.89-2.76)$ \\
\hline
\end{tabular}


TABLE 2. CAA After $1 \mathrm{yr}(\mathrm{n}=10 / 177)$ : Numbers at High Risk for CAA After 1 yr According to Different Scores and Indicators of Prognostic Validity for the Respective Scores

\begin{tabular}{|c|c|c|c|c|c|c|c|}
\hline $\begin{array}{l}\text { High-risk } \\
\text { According } \\
\text { to Score }\end{array}$ & $\begin{array}{c}\text { Aneurysm } \\
\text { High-risk } \\
\text { Children } \\
\text { n }(\%)\end{array}$ & $\begin{array}{l}\text { Relative Risk: } \\
\text { High- vs. } \\
\text { Low-risk Cases } \\
(95 \% \text { CI })\end{array}$ & Sensitivity & Specificity & $\begin{array}{l}\text { Positive } \\
\text { Predictive } \\
\text { Value }\end{array}$ & $\begin{array}{l}\text { Negative } \\
\text { Predictive } \\
\text { Value }\end{array}$ & $\begin{array}{c}\text { Positive } \\
\text { Likelihood Ratio } \\
(95 \% \text { CI })\end{array}$ \\
\hline $\begin{array}{l}\text { Kobayashi }>4 \\
\mathrm{n}=37\end{array}$ & $3(8)$ & $1.62(0.44-5.97)$ & 0.30 & 0.80 & 0.08 & 0.95 & $1.50(0.55-3.98)$ \\
\hline $\begin{array}{l}\text { Kobayashi }>3 \\
\mathrm{n}=60\end{array}$ & $5(8)$ & $1.95(0.59-6.47)$ & 0.50 & 0.67 & 0.08 & 0.96 & $1.52(0.79-2.93)$ \\
\hline $\begin{array}{l}\text { Sano } \\
\mathrm{n}=18\end{array}$ & $2(11)$ & $2.21(0.51-9.61)$ & 0.20 & 0.90 & 0.11 & 0.95 & $2.00(0.56-7.85)$ \\
\hline $\begin{array}{l}\text { Egami } \\
n=50\end{array}$ & $4(8)$ & $1.69(0.50-5.75)$ & 0.40 & 0.72 & 0.08 & 0.95 & $1.43(0.65-3.23)$ \\
\hline
\end{tabular}

TABLE 3. Laboratory Values for Refractory and Nonrefractory Patients $(\mathrm{n}=301)$

\begin{tabular}{|c|c|c|c|}
\hline Laboratory & $\begin{array}{c}\text { Refractory: Yes } \\
(\mathrm{n}=47) \\
\text { Mean }\end{array}$ & $\begin{array}{c}\text { Refractory: No } \\
(\mathrm{n}=245) \\
\text { Mean }\end{array}$ & $\begin{array}{l}P \text { value } \\
t \text { test }\end{array}$ \\
\hline Albumin (g/dL) & 2.65 & 3.04 & 0.008 \\
\hline $\mathrm{AST}(\mathrm{U} / \mathrm{L})$ & 162.81 & 94.86 & 0.049 \\
\hline Total protein (g/dL) & 8.18 & 7.58 & 0.825 \\
\hline $\operatorname{ALT}(\mathrm{U} / \mathrm{L})$ & 150.10 & 93.54 & 0.024 \\
\hline Gamma-GT (U/L) & 119.24 & 82.40 & 0.156 \\
\hline Bilirubin (mg/L) & 8.42 & 6.10 & 0.415 \\
\hline $\mathrm{CRP}(\mathrm{mg} / \mathrm{L})$ & 160.88 & 104.28 & $<0.0001$ \\
\hline Sodium $(\mathrm{mmol} / \mathrm{L})$ & 132.26 & 134.18 & 0.006 \\
\hline Potassium (mmol/L) & 3.91 & 4.23 & 0.130 \\
\hline $\operatorname{ESR}(\mathrm{mm} / \mathrm{h})$ & 112.22 & 90.68 & 0.003 \\
\hline 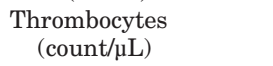 & 734.57 & 547.58 & $<0.0001$ \\
\hline Hemoglobin (g/dL) & 8.81 & 10.33 & $<0.0001$ \\
\hline WBC count $($ count $/ \mu \mathrm{L})$ & 23.13 & 16.77 & 0.002 \\
\hline Neutrophils (\%) & 77.53 & 68.66 & 0.059 \\
\hline $\begin{array}{l}\text { Gallbladder hydrops } \\
\text { (n) }\left(\chi^{2} \text { test }\right)\end{array}$ & 11 & 21 & 0.006 \\
\hline
\end{tabular}

ALT indicates alanine aminotransferase; ESR, erythrocyte sedimentation rate; WBC, white blood cell count.

these, we calculated Random Forests, ${ }^{15}$ a statistical method that expands on well-known classification and regression trees. ${ }^{16}$ classification and regression trees (CART) uses a given set of covariates and identifies optimal cutoff values to best divide a data set into 2 groups relating to a response variable (eg, refractory "yes" or "no"). Based on different cutoffs, Random Forests averages a large number of classification and regression tree decisions to provide an efficient and computationally stable method for detecting the most predictive variables for explaining the respective response variable without also providing cutoff values.

\section{RESULTS}

Out of 442 presumed KD cases reported, 342 were classified as complete and 26 as incomplete according to the AHA guidelines (Fig. 1). From the total, 72 children did not meet the required clinical definition criteria. Additionally, 2 Japanese children were excluded. All 301 patients included in our analysis had had at least 1 IVIG dose and were labeled as "Kawasaki cases with standard therapy." Follow-up for 1 year was available for 177 of the children. Cases with and without follow-up did not differ with respect to sociodemographics or to clinical symptoms during the acute phase (Table, Supplemental Digital Content 2, http://links.lww.com/INF/ C970). Among the follow-up cases, there was 1 case treated with

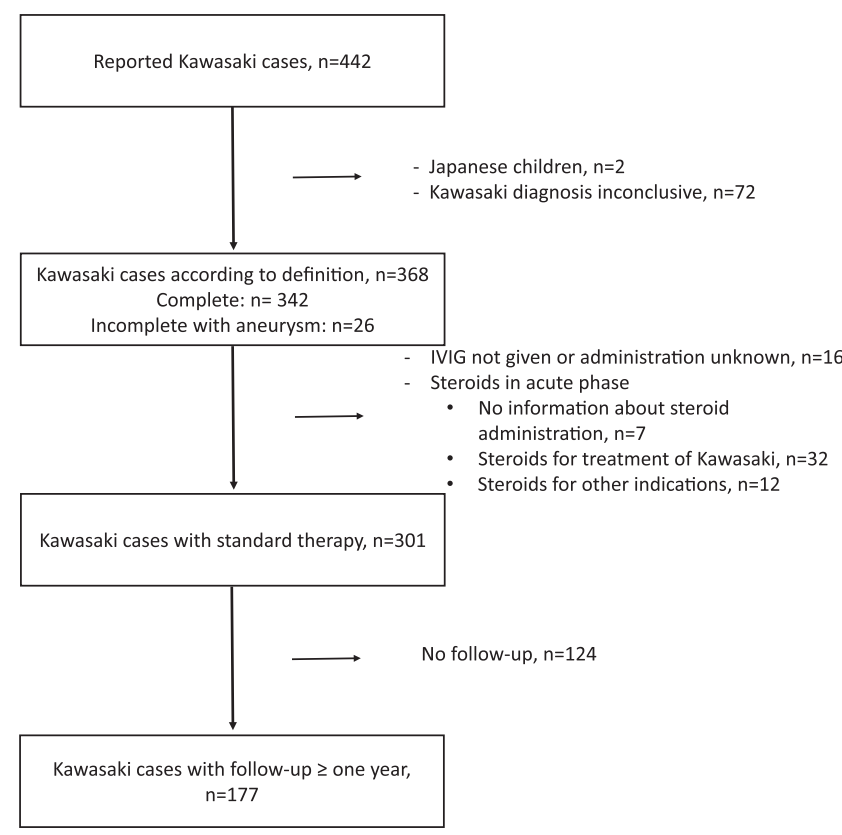

FIGURE 1. Flow chart of the study cohort.

infliximab, methotrexate and anakinra. This child already had had giant CAA early in the course of the disease, and this CAA persisted at the 1-year follow-up. In fact, according to all scores when treated with IVIG, this child would have been assigned as high risk.

Among the cases, the proportion of boys was $65 \%$. Ethnic background was available in $90 \%$ of cases and showed a breakdown of $95 \%$ Caucasian, 3\% Asian and 2\% black African.

Over half the patients (189 or $63 \%$ ) were 1 to 4 years old, $47(16 \%)$ were refractory to IVIG, $67(22 \%)$ had CAA in the acute phase, 22 (13\% had CAA after 4 weeks) and $10(6 \%)$ had CAA after 1 year. High-risk status was assigned to $21 \%$ of the cases according to the Kobayashi score $>4$ (33\% Kobayashi score $>3$ ), $9 \%$ according to the Sano score and $28 \%$ according to the Egami score (Table 4).

All scores indicated an increased risk for being refractory (all 95\% CI's excluded 1: no effect, Table 5). The LR+ of the Sano score was 4.67 (95\% CI: $2.39-9.19$ ). This indicates a $46 \%$ probability of being refractory, given that the Sano score is high (post-test probability) as compared with the $16 \%$ probability of being refractory in the entire cohort without the application of any score (pretest probability). The respectively predicted post-test probabilities for the Kobayashi score $>4$ were $31 \%(>3,25 \%)$ and $27 \%$ for the Egami score. 
TABLE 4. General Patient and Score Defining Characteristics of the Included Standard Kawasaki Cases $(\mathrm{n}=301)$

\begin{tabular}{|c|c|}
\hline General Characteristics & $\mathrm{n}(\%)$ \\
\hline Gender: boys & $196(65)$ \\
\hline \multicolumn{2}{|l|}{ Age (yr) } \\
\hline$<1$ & $52(17)$ \\
\hline $1-4$ & $189(63)$ \\
\hline$\geq 5$ & $60(20)$ \\
\hline Refractory to IVIG: yes & $47(16)$ \\
\hline \multicolumn{2}{|l|}{ CAA } \\
\hline In acute phase & $67(22)$ \\
\hline After $4 \mathrm{wk}^{*}$ & $22(13)$ \\
\hline After $1 \mathrm{yr} \dagger$ & $10(6)$ \\
\hline Kobayashi score $>4 />3$ & $64(21) / 99(33)$ \\
\hline Days of illness at initial treatment $\leq 4$ & $82(27)$ \\
\hline Age $\leq 1 \mathrm{yr}$ & $52(17)$ \\
\hline Sodium $\leq 133 \mathrm{mmol} / \mathrm{L}$ & $103(34)$ \\
\hline $\mathrm{AST} \geq 100 \mathrm{IU} / \mathrm{L}$ & $62(21)$ \\
\hline Neutrophils $\geq 80 \%$ & $65(22)$ \\
\hline $\mathrm{CRP} \geq 10 \mathrm{mg} / \mathrm{dL}$ & $141(47)$ \\
\hline Thrombocytes $\leq 300 \times 10^{9} / \mathrm{L}$ & $35(12)$ \\
\hline Sano score $>1$ & $28(9)$ \\
\hline $\mathrm{CRP} \geq 7 \mathrm{mg} / \mathrm{dL}$ & $185(62)$ \\
\hline Bilirubin $\geq 0.9 \mathrm{mg} / \mathrm{dL}$ & $20(7)$ \\
\hline $\mathrm{AST} \geq 200 \mathrm{IU} / \mathrm{L}$ & $27(9)$ \\
\hline Egami score $>2$ & $85(28)$ \\
\hline Age $\leq 6 \mathrm{mo}$ & $24(8)$ \\
\hline Days of illness at initial treatment $\leq 4$ & $82(27)$ \\
\hline $\mathrm{CRP} \geq 8 \mathrm{mg} / \mathrm{dL}$ & $166(55)$ \\
\hline Thrombocytes $\leq 300 \times 10^{9} / \mathrm{L}$ & $35(12)$ \\
\hline $\mathrm{ALT} \geq 80 \mathrm{IU} / \mathrm{L}$ & $102(34)$ \\
\hline
\end{tabular}

*Follow-up 4 weeks after onset of disease: $\mathrm{N}=175$.

$\dagger$ Follow-up 1 year after onset of disease: $\mathrm{N}=177$

ALT indicates alanine aminotransferase.

After 4 weeks, only the Sano score indicated an increased risk for aneurysm. After 1 year, none of the scores predicted an increased risk. Accordingly, the LRs + for CAA after 4 weeks were only significantly increased for the Sano score (Tables 1 and 2). Being refractory to IVIG was associated with an increased risk for CAA after 4 weeks (Relative Risk $=2.46,95 \%$ CI: $1.17-5.08$ ); however, there was no association with an increased risk of having an aneurysm after 1 year $(\mathrm{RR}=1.33,95 \% \mathrm{CI}$ : 0.37-4.68).

As shown in Table 3, several laboratory values and hydrops of the gallbladder were significantly associated with being refractory. Laboratory values measured on a continuous scale were fed into the analysis without prior dichotomization. Therefore, no cutoffs for these parameters are provided. The model underlying the Random Forest method using hydrops of the gallbladder, albumin, AST, alanine aminotransferase, CRP, sodium, erythrocyte sedimentation rate, thrombocytes, hemoglobin and white blood cell count is based on repetitive CART trees and provides a summary estimate. The Random Forest method identified 14 patients as high-risk patients. The most discriminating variable was hemoglobin, followed by AST and thrombocytes. The respective specificity for the high-risk group was 98\%, accounting for a high LR+ of 15 (CI: 5.10-31.15). Unfortunately, sensitivity achieved was only $30 \%$ - that is, however not higher than that for the established scores (Table 6).

\section{DISCUSSION}

By applying different scores for KD in a primarily Caucasian population, we were able to assess and compare their predictive value regarding being refractory in relation to standard IVIG and regarding risk of mid- or long-term (1 year) CAA. Although high-risk cases as assigned by all scores were associated with an increased risk for being refractory, the prognostic value of these scores was low as indicated by poor sensitivity and by a small LR+. This was irrespective of the cutoff values applied by the Kobayashi score. In terms of predicting CAA, only the Sano Score showed a significantly elevated risk and $\mathrm{LR}+$ for CAA after 4 weeks but with poor sensitivity and positive predictive value. Although several laboratory values and hydrops of the gallbladder were significantly associated with being refractory in our mainly Caucasian patient cohort, the Random Forest approach unfortunately, did not yield a more valid prognostic score.

We have focused the discussion on the outcome of being refractory, because the 3 Japanese scores were originally designed to detect resistance to IVIG. For a number of studies, reported in the literature, we have listed the published study characteristics and prognostic indicators in Table 7, Supplemental Digital Content, http://links.lww. com/INF/C975. Although all studies gave sensitivity and specificity, few showed the positive and negative predictive values and none the LR + . While the assessed scores appeared to be fairly predictive in Japanese children, ${ }^{5-8,17,18}$ they seemed to be of less clinical relevance in non-Japanese Asian KD children. ${ }^{19,20}$ A study evaluating all 3 scores in Korean KD children even yielded somewhat lower sensitivities for IVIG nonresponsiveness than our study did (range of $28 \%-34 \%$ ). In a KD patient cohort from east China, both scores' sensitivity (Egami and Kobayashi) was $57.1 \%$ with regard to response to IVIG. In Caucasian children, these scores also failed to validly predict high risk in KD children (sensitivity through all scores was $26 \%-58 \%$ ). A Medline search on the phrase "Kawasaki disease and scores and/or IVIG resistance" yielded 5 publications that focused primarily on Caucasian children. Three publications were from Europe $e^{10,21,22}$ and 2 from the United States..$^{9,23}$ Regarding being refractive to IVIG, an English ${ }^{10}$ and Polish ${ }^{22}$ study evaluated the Kobayashi score in a monocentric, small sample size study; meanwhile, a Catalonian study group assessed the

TABLE 5. KD Cases Refractory to IVIG ( $n=47 / 301)$ : Numbers at High Risk for Being Refractory According to Different Scores and Indicators of Prognostic Validity for the Respective Scores

\begin{tabular}{|c|c|c|c|c|c|c|c|}
\hline $\begin{array}{l}\text { High-risk } \\
\text { According } \\
\text { to Score }\end{array}$ & $\begin{array}{c}\text { Refractory } \\
\text { High-risk } \\
\text { Children } \\
\text { n }(\%)\end{array}$ & $\begin{array}{c}\text { Relative Risk: } \\
\text { High- vs. } \\
\text { Low-risk Cases } \\
(95 \% \text { CI })\end{array}$ & Sensitivity & Specificity & $\begin{array}{l}\text { Positive } \\
\text { Predictive } \\
\text { Value }\end{array}$ & $\begin{array}{c}\text { Negative } \\
\text { Predictive } \\
\text { Value }\end{array}$ & $\begin{array}{c}\text { Positive } \\
\text { Likelihood Ratio } \\
(95 \% \mathrm{CI})\end{array}$ \\
\hline $\begin{array}{l}\text { Kobayashi }>4 \\
\mathrm{n}=64\end{array}$ & $20(31)$ & $2.74(1.65-4.56)$ & 0.43 & 0.83 & 0.31 & 0.89 & $2.53(1.60-3.77)$ \\
\hline $\begin{array}{l}\text { Kobayashi }>3 \\
\mathrm{n}=99\end{array}$ & $25(25)$ & $2.32(1.38-3.90)$ & 0.53 & 0.71 & 0.25 & 0.89 & $1.83(1.31-2.54)$ \\
\hline $\begin{array}{l}\text { Sano } \\
\mathrm{n}=28\end{array}$ & $13(46)$ & $3.73(2.25-6.19)$ & 0.28 & 0.94 & 0.46 & 0.88 & $4.67(2.39-9.19)$ \\
\hline $\begin{array}{l}\text { Egami } \\
n=85\end{array}$ & $23(27)$ & $2.44(1.46-4.07)$ & 0.49 & 0.76 & 0.27 & 0.89 & $2.04(1.39-2.88)$ \\
\hline
\end{tabular}


TABLE 6. Outcome Refractory (47/301): High-risk Classification by Random Forests, Numbers Exposed, Risk for Being Refractory Related to High Risk and Prognostic Validity of the Classification

\begin{tabular}{|c|c|c|c|c|c|c|c|}
\hline $\begin{array}{l}\text { High Risk } \\
\text { According to }\end{array}$ & $\begin{array}{c}\text { Refractory } \\
\text { High-risk } \\
\text { Children } \\
\text { n }(\%)\end{array}$ & $\begin{array}{c}\text { Relative Risk: } \\
\text { High- vs. } \\
\text { Low-risk Cases } \\
(95 \% \text { CI })\end{array}$ & Sensitivity & Specificity & $\begin{array}{c}\text { Positive } \\
\text { Predictive } \\
\text { Value }\end{array}$ & $\begin{array}{c}\text { Negative } \\
\text { Predictive } \\
\text { Value }\end{array}$ & $\begin{array}{c}\text { Positive } \\
\text { Likelihood Ratio } \\
(95 \% \text { CI })\end{array}$ \\
\hline $\begin{array}{l}\text { Random } \\
\quad \text { Forests } \\
\mathrm{n}=20\end{array}$ & $14(70)$ & $5.96(3.88-9.17)$ & 0.30 & 0.98 & 0.70 & 0.88 & $15.00(5.10-31.15)$ \\
\hline
\end{tabular}

Egami score in a population-based study. ${ }^{21}$ The English study assessing the Kobyashi score for prediction of CAA in Caucasian children was based on small numbers $(n=20)$ and confined for CAA in the acute phase only. Loomba et $\mathrm{al}^{23}$ evaluated the Egami score vis-à-vis predicting IVIG resistance in KD among different ethnicities in a Midwest US population. Although they did not find a clinically meaningful difference among the different ethnic groups, their cohort included just 9 children of Asian origin. Among the studies discovered, only the US study by Sleeper at $\mathrm{al}^{9}$ may be seen as comparable with ours with respect to assessment of all 3 scores in their prediction of IVIG resistance and CAA ( 5 weeks after the acute phase of illness). Here, only the Kobayashi score seemed to significantly predict a high coronary artery $\mathrm{Z}$ score $(P<0.05)$. The association, however, was weak, showing a Spearman correlation coefficient of just 0.29.

\section{STRENGTH AND LIMITATIONS}

Our study is the first European study to evaluate all 3 established Japanese risk scores in relation to a cohort of primarily Caucasian children. It is also the first to provide data on the utility of these scores in predicting persistence of aneurysm after standard therapy up to 1 year after acute KD. Originally, the 3 Japanese scores were designed to detect resistance to IVIG. However, the most important impact of KD on long-term morbidity is the persistence of CAA. To our knowledge, to date, the association between high-risk cases as identified by the Japanese scores and persistent aneurysm up to 1 year after the acute illness has not been evaluated. In our population, the rates of CAA were $13 \%$ after 4 weeks and $6 \%$ after 1 year. This is in accordance with CAA rates reported after IVIG introduction in other studies. ${ }^{24,25}$ Because reporting physicians did not report coronary artery diameters for all patients, we had to rely on the validity of their diagnosis. For a subsample of 15 of 22 cases with CAA at 4 weeks, we were able to validate the physicians' diagnosis of CAA since specific coronary artery dimensions were reported. We used the $\mathrm{Z}$ score equation proposed by Dallaire et al. ${ }^{14}$ In all 15 cases, the $Z$ score was $>2.5$.

Because of lack of statistical power, our study did not allow for a meaningful assessment of the prognostic validity of these scores in relation to aneurysm after 4 weeks and 12 months. This most likely explains our failure to identify an association between being refractory and CAA after 12 months. Because our study originally was designed to assess the incidence of $\mathrm{KD}$ in Germany, statistical power calculations regarding the predictive value of different scores in identifying CAA had not been performed.

We conducted a number of sensitivity analyses: Among the 301 cases in the main analysis, we reran the score test statistics only for those with complete data on all parameters. This yielded results similar to those in the main analysis (Table, Supplemental Digital Content 1, http://links.lww.com/INF/C969). To assess external validity with respect to the excluded children, we ran the score analyses for all children combined (Tables, Supplemental Digital Content 3-5, http://links.lww.com/INF/C971; http://links.
lww.com/INF/C972; http://links.lww.com/INF/C973). This showed nearly identical results. We additionally compared clinical characteristics in excluded children vis-à-vis those included in the main analysis. These data show that exclusion of cases given steroids or cases for whom there was lacking information on steroid administration, did not account for lack of external validity by confining the main analysis to KD cases at a lower risk (Table, Supplemental Digital Content 6, http://links.lww.com/INF/C974).

\section{CLINICAL IMPLICATIONS OF THIS STUDY}

A recent meta-analysis confirmed the effectiveness of corticosteroids in treating high-risk children. ${ }^{26,27}$ The challenge, however, is to identify children at high risk for KD in non-Japanese children. This is again outlined in the recent AHA's scientific statement from the year 2017. ${ }^{11}$ Adjunctive administration of corticosteroid was only recommended if high-risk patients can be identified. ${ }^{11}$ Our in-depth assessment of the 3 major Japanese scores, plus an additional data-driven score, did not indicate a reliable tool for predicting failure to respond to IVIG in primarily Caucasian (ie, non-Japanese) children. Because valid scores to identify high-risk KD children in Caucasian children are unavailable, supplementing IVIG with steroids for all children can be supported - as suggested by a recent Cochrane review ${ }^{28}$ - at least until those who do not need this therapy escalation can be identified.

\section{ACKNOWLEDGMENTS}

The authors thank all the participating pediatricians reporting KD cases and Natalie Diffloth for English language editing.

\section{REFERENCES}

1. Newburger JW, Takahashi M, Gerber MA, et al; Committee on Rheumatic Fever, Endocarditis, and Kawasaki Disease, Council on Cardiovascular Disease in the Young, American Heart Association. Diagnosis, treatment, and long-term management of Kawasaki disease: a statement for health professionals from the Committee on Rheumatic Fever, Endocarditis, and Kawasaki Disease, Council on Cardiovascular Disease in the Young, American Heart Association. Pediatrics. 2004;114:1708-1733.

2. Sundel RP, Baker AL, Fulton DR, et al. Corticosteroids in the initial treatment of Kawasaki disease: report of a randomized trial. J Pediatr. 2003;142:611-616.

3. Newburger JW, Sleeper LA, McCrindle BW, et al; Pediatric Heart Network Investigators. Randomized trial of pulsed corticosteroid therapy for primary treatment of Kawasaki disease. N Engl J Med. 2007;356:663-675.

4. Kobayashi T, Saji T, Otani T, et al; RAISE study group investigators. Efficacy of immunoglobulin plus prednisolone for prevention of coronary artery abnormalities in severe Kawasaki disease (RAISE study): a randomised, open-label, blinded-endpoints trial. Lancet. 2012;379:1613-1620

5. Kobayashi T, Inoue Y, Takeuchi K, et al. Prediction of intravenous immunoglobulin unresponsiveness in patients with Kawasaki disease. Circulation. 2006;113:2606-2612.

6. Kobayashi T, Inoue Y, Otani T, et al. Risk stratification in the decision to include prednisolone with intravenous immunoglobulin in primary therapy of Kawasaki disease. Pediatr Infect Dis J. 2009;28:498-502. 
7. Egami K, Muta H, Ishii M, et al. Prediction of resistance to intravenous immunoglobulin treatment in patients with Kawasaki disease. J Pediatr. 2006;149:237-240.

8. Sano T, Kurotobi S, Matsuzaki K, et al. Prediction of non-responsiveness to standard high-dose gamma-globulin therapy in patients with acute Kawasaki disease before starting initial treatment. Eur J Pediatr. 2007;166:131-137.

9. Sleeper LA, Minich LL, McCrindle BM, et al; Pediatric Heart Network Investigators. Evaluation of Kawasaki disease risk-scoring systems for intravenous immunoglobulin resistance. J Pediatr. 2011;158:831-835.e3.

10. Davies S, Sutton N, Blackstock S, et al. Predicting IVIG resistance in UK Kawasaki disease. Arch Dis Child. 2015;100:366-368.

11. McCrindle BW, Rowley AH, Newburger JW, et al; American Heart Association Rheumatic Fever, Endocarditis, and Kawasaki Disease Committee of the Council on Cardiovascular Disease in the Young; Council on Cardiovascular and Stroke Nursing; Council on Cardiovascular Surgery and Anesthesia; and Council on Epidemiology and Prevention. Diagnosis, treatment, and long-term management of Kawasaki Disease: A Scientific Statement for Health Professionals From the American Heart Association. Circulation. 2017;135:e927-e999.

12. Jakob A, Whelan J, Kordecki M, et al. Kawasaki Disease in Germany: a prospective, population-based study adjusted for underreporting. Pediatr Infect Dis J. 2016;35:129-134.

13. Goto T, Sano T, Kojo T, et al. Time course of cardiac lesions due to Kawasaki disease in Japan: 22nd nationwide survey (2011-2012). Pediatr Int. 2016;58:1274-1276.

14. Dallaire F, Dahdah N. New equations and a critical appraisal of coronary artery Z scores in healthy children. J Am Soc Echocardiogr. 2011;24:60-74.

15. Breiman L. Random Forests. Machine Learn. 2001;45:5-32.

16. Breiman L., Friedman J., Stone Ch. et al. Classification and Regression Trees. Chapman and Hall/CRC Press, 1984

17. Kanamitsu K, Kakimoto H, Shimada A, et al. Verification of risk scores to predict i.v. immunoglobulin resistance in incomplete Kawasaki disease. Pediatr Int. 2016;58:146-151.
18. Seki M, Kobayashi T, Kobayashi T, et al. External validation of a risk score to predict intravenous immunoglobulin resistance in patients with Kawasaki disease. Pediatr Infect Dis J. 2011;30:145-147.

19. Kim BY, Kim D, Kim YH, et al. Non-responders to intravenous immunoglobulin and coronary artery dilatation in Kawasaki Disease: predictive parameters in Korean Children. Korean Circ J. 2016;46:542-549.

20. Tang Y, Yan W, Sun L, et al. Prediction of intravenous immunoglobulin resistance in Kawasaki disease in an East China population. Clin Rheumatol. 2016;35:2771-2776

21. Sánchez-Manubens J, Antón J, Bou R, et al; Kawasaki Disease in Catalonia Working Group. Role of the Egami score to predict immunoglobulin resistance in Kawasaki disease among a Western Mediterranean population. Rheumatol Int. 2016;36:905-910.

22. Berdej-Szczot E, Małecka-Tendera E, Gawlik T, et al. Risk factors of immunoglobulin resistance and coronary complications in children with Kawasaki disease. Kardiol Pol. 2017;75:261-266.

23. Loomba RS, Raskin A, Gudausky TM, et al. Role of the Egami score in predicting intravenous immunoglobulin resistance in Kawasaki disease among different ethnicities. Am J Ther. 2016;23:e1293-e1299.

24. Newburger JW, Takahashi M, Burns JC, et al. The treatment of Kawasaki syndrome with intravenous gamma globulin. $N$ Engl J Med. 1986;315:341-347.

25. Furusho K, Kamiya T, Nakano H, et al. High-dose intravenous gammaglobulin for Kawasaki disease. Lancet. 1984;2:1055-1058.

26. Sundel R. Clarifying the role of corticosteroids in Kawasaki disease. JAMA Pediatr. 2016;170:1140-1142.

27. Chen S, Dong Y, Kiuchi MG, et al. Coronary artery complication in Kawasaki disease and the importance of early intervention: a systematic review and meta-analysis. JAMA Pediatr. 2016;170:1156-1163.

28. Wardle AJ, Connolly GM, Seager MJ, et al. Corticosteroids for the treatment of Kawasaki disease in children. Cochrane Database Syst Rev. 2017; 1:CD011188. 